\title{
Effect of undernutrition on the ability of the sheep rumen to absorb VFA
}

\author{
R Perrier ${ }^{1}, M_{\text {Doreau }}{ }^{1}$, J Fléchet ${ }^{2}$ \\ 1 INRA, Laboratoire Sous-Nutrition des Ruminants, \\ 2 INRA, Département Élevage et Nutrition des Herbivores, \\ Theix, 63122 Saint-Genès-Champanelle, France
}

The aim of this experiment was to determine if VFA absorption in the rumen varies when the animal is underfed. The ability of the rumen to absorb the same quantity of VFA with animals previously fed 2 levels of intake was tested.

Two sheep weighing 65 and $69 \mathrm{~kg}$, fitted with a large rumen cannula $(7.5 \mathrm{~cm})$ and an abomasal cannula, were used in this experiment and were fed a meadow hay. The experiment comprised 2 weeks of adaptation to the hay and 2 measurement periods $\mathrm{P} 1$ and $\mathrm{P} 2$ of 4 weeks each. During $P 1$ and $P 2$ animals received maintenance (level 1) and half maintenance (level 0.5) energy and nitrogen requirements, respectively. Absorption was measured once or twice a week during $P 1$ and at the end of P2 (total 12 trials) as described by Gäbel and Martens (1986). The sheep rumen was emptied and washed with warm saline solution. The rumen content was kept at $39^{\circ} \mathrm{C}$ and returned to the numen at the end of the experiment. A solution $(3 \mathrm{I})$ buffered at $\mathrm{pH} 6.25$ containing VFA (C2: $57.1, \mathrm{C3}: 49.2$ and C4: 7.4 $\mathrm{mmol} / \mathrm{l})$ and CoEDTA (4.4 mg Co/l) was introduced in the rumen in one go and regularly sampled for $3 \mathrm{~h}$. The solution was not warmed to avoid VFA volatilization. Saliva was continuously removed by a saliva collector introduced in the esophagus and was directed into the abomasum. As verified in a preliminary experiment, the quantity of CoEDTA in the rumen was considered as constant throughout the experiment and then volume variations due to water movement were calculated from CoEDTA concentrations.
Ratios between the VFA concentrations (C2/C3, C3/C4, C2/C4) were not different between animals. All ratios increased with time showing that the absorption rate order is $\mathrm{C} 4>$ $\mathrm{C} 3>\mathrm{C} 2$. The quantity of VFA absorbed per hour for each VFA was independent of $\mathrm{pH}$ and time. Percentages of total VFA absorbed (\% of initial) were higher $(P<0.01)$ at level 1 than at level 0.5 . Mean absorption rates (\% initial $/ \mathrm{h}$ ) of $\mathrm{C} 3$ and $\mathrm{C} 4$ were higher $(P<0.05)$ at level 1 than at level 0.5 (C3: 19.4 and $C 4: 21.3 \% / h$ vs 12.9 and $14.2 \% / \mathrm{h}$ ). The mean absorption rate of $\mathrm{C} 2$ presented the same trend though the difference was not significant $(18.0$ and $11.5 \% / \mathrm{h})$. CoEDTA and VFA concentration evolution showed that water and VFA were immediately absorbed to a large extent and then in part released in the rumen during the first hour. This experiment showed that absorption of the same amount of VFA tends to be reduced after undernutrition. During undernutrition, both rumen VFA concentration and metabolic activity are reduced. VFA are known to stimulate epithelium cell proliferation (Sakata and Tamate, 1979). A reduction in the number or in the enzymatic activity of the epithelium cells may explain the decreased absorption during undernutrition.

Gäbel G, Martens H (1986) J Anim Physiol Anim Nutr 55, 278-287

Sakata T, Tamate H (1979) J Dairy Sci 62, 4952 